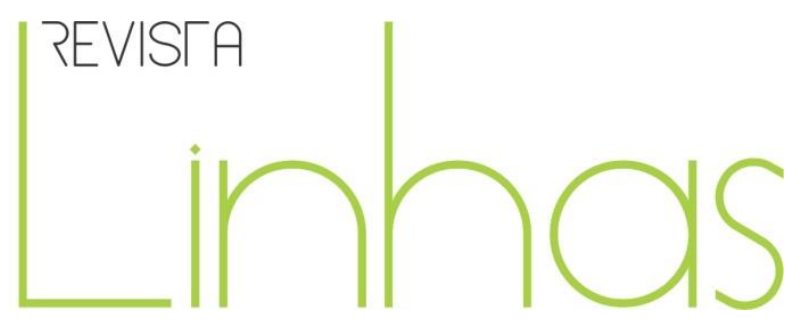

\title{
Mediações entre a governança global e a responsabilização docente pela redenção educacional
}

\begin{abstract}
Resumo
Com a reorientação da gestão educacional pela matriz da governança em escala global, proliferaram-se clamores que responsabilizam os professores pela melhoria da qualidade educacional e dos resultados da aprendizagem, gerando ampla mobilização pela constituição de iniciativas políticas endereçadas ao magistério. Visando caracterizar tendências e desafios desse novo cenário sociopolítico e seus desdobramentos, neste artigo abordam-se as determinações, implicações e mediações desse processo. Para tanto, analisaram-se relatórios, manifestações oficiais e documentos institucionais, que demonstram que a veiculação da matriz da governança constitui um poderoso sistema de direção política e coesão social, que estabelece novos métodos de coordenação, pautados em uma feição participativa e inclusiva. Trata-se da combinação subordinada da administração das questões sociais aos mecanismos de elevação da lucratividade das corporações capitalistas, que, sob a justificativa de ampliar a capacidade institucional do Estado e estimular a responsabilidade social, tem inserido grupos privados na gestão dos serviços públicos. Devido à sua relevância, não apenas por forjar as condições técnicas, mas também pelo potencial de inculcação ideológica da classe trabalhadora, o professor, içado à condição de redentor, tem sido realçado como imprescindível para compatibilizar a educação compulsória às demandas da economia global. Conclui-se que a propagação de proposições multilaterais para reformar a gestão da educação e dos professores está associada à peremptória necessidade de salvaguardar o projeto histórico capitalista, por meio de ações que formem a força de trabalho, ampliem a lucratividade dos oligopólios e efetuem a gestão do social.
\end{abstract}

Palavras-chave: Educação e estado. Políticas e gestão da educação. Professores. Governança pública.

\section{Para citar este artigo:}

BRITO NETO, Anibal Correia. Mediações entre a governança global e a responsabilização docente pela redenção educacional. Revista Linhas. Florianópolis, v. 21, n. 46, p. 117-144, maio/ago. 2020. 


\title{
Mediations between global governance and teacher's accountability for the redemption of education
}

\begin{abstract}
Following the redirection of educational management by the governance matrix in a global scale, a proliferation of claims for the improvement of educational quality and the learning outcomes have emerged, holding teachers accountable and generating a wide mobilization for the constitution of political initiatives addressed at the magisterium. Aiming at characterize tendencies and challenges related to this new socio-political scenario and its developments, this article addresses the determinations, implications and mediations of this process. For this purpose, it analysis reports, official speeches and institutional documents in order to demonstrate that the dissemination of governance matrix forms a powerful system of political direction and social cohesion, establishing new methods of coordination, guided by participatory and inclusive features. It represents the subordinate combination of the administration of social issues with mechanisms to increase the profitability of capitalist corporations, which, under the excuse of expanding the institutional capacity of the State and stimulate social responsibility, has engaged private groups in the management of public services. Due to its relevance, not just by forging the technical conditions, but also by the potential ideological inculcation of the working class, the teacher, hoisted to the condition of redeemer, has been enhanced as indispensable to reconcile compulsory education to the demands of the global economy. This study has shown that the spread of multilateral propositions to reform the management of education and teachers is associated with the peremptory need to safeguard the historical capitalist project, through actions that form the workforce, increase the profitability of oligopolies and undertake the social management.
\end{abstract}

Keywords: Education and state. Education policies and management. Teachers. Public governance. 


\section{Introdução}

Este estudo ${ }^{1}$ trata das determinações, implicações e mediações entre os processos de governança global e a constituição de iniciativas políticas endereçadas à questão docente. Aborda, de modo específico, a mudança educacional verificada na transição para o século XXI, a qual deflagrou os clamores que passaram a depositar na atividade docente a responsabilidade central pela melhoria da qualidade educacional e dos resultados da aprendizagem.

Nesse contexto, analisa o complexo sistema engendrado, o qual tem resultado na implementação de campanhas, prêmios e comemorações; na realização de eventos e fóruns; na assunção de compromissos e estratégias; e, principalmente, na veiculação de um elevado montante de conhecimentos/dados que tem como mote central o tema docente.

Trata-se, portanto, de uma vasta gama de atores globais e nacionais envolvidos em ações transfronteiriças voltadas ao professorado através das lindes dos Estados nacionais, denotando grande ênfase em relação àquela dimensão com amplo potencial reprodutivo dos desígnios educativos e formativos, isto é, o trabalho educativo, o que coloca em litígio a afirmação da sua positividade como "ato de produzir, direta e intencionalmente, em cada indivíduo singular, a humanidade que é produzida histórica e coletivamente pelo conjunto dos homens." (SAVIANI, 2011, p. 13).

Como demonstrou Taffarel (1993), o campo do trabalho educativo está atravessado integralmente pelas contradições do confronto de classes sociais. Logo, se por um lado, a sua análise sobre os traços essenciais do trabalho educativo revelou processos que legitimam as relações sociais vigentes no modo capitalista de produção, por outro lado, também apontou possibilidades concretas de construção de outras referências para organização do trabalho educativo em articulação com a luta maior pela constituição de novas relações sociais no mundo do trabalho e da produção (TAFFAREL, 1993).

\footnotetext{
1 Este artigo é derivado e adaptado da Tese de Doutorado intitulada "Política Nacional de Formação de Professores no Brasil (2003-2016) como expressão da governança global” (BRITO NETO, 2018), defendida no Programa de Pós-Graduação em Educação da Universidade Federal de Santa Catarina, a qual contou com financiamento da Coordenação de Aperfeiçoamento de Pessoal de Nível Superior (Capes) e do Governo do Estado do Pará.
} 
Sendo assim, em coerência com a premissa materialista histórica resgatada por Lombardi (2005), segundo a qual a compreensão dos fenômenos educacionais ou de qualquer outra dimensão da vida social só seriam possíveis a partir da sua inserção no contexto que possibilitou a sua concepção, o ponto de partida desta exposição concretiza-se na apreensão do contexto de transformações societárias decorrentes da crise sistêmica que tem atravessado toda a estrutura da "ordem do capital" na contemporaneidade, em especial no âmbito das estratégias que têm sido desenvolvidas com o propósito de salvaguardar o sistema produtivo, tais como os processos de governança global instaurados a partir da década de 1990.

Portanto, atento ao entrelaçamento dos múltiplos fatores que permeiam a mobilização em torno da questão docente, o estudo em tela se materializou em função do seguinte objetivo geral: elucidar as mediações fundamentais entre os processos de governança global, a prioridade outorgada à questão docente no discurso educacional contemporâneo e o desenvolvimento de ações transfronteiriças endereçadas às políticas docentes dos Estados nacionais.

Em vista dessa finalidade maior, os objetivos específicos da pesquisa consistiram em: caracterizar os nexos e determinações entre os ajustes estruturais operados no sistema capitalista a partir da década de 1970 e o engendramento do fenômeno da governança na década de 1990; caracterizar a estratégia político-educacional de responsabilização da categoria docente forjada na última transição secular; e identificar os parâmetros teórico-metodológicos constitutivos das principais iniciativas políticas endereçadas à questão docente nesse processo.

Como perspectiva metodológica, com o propósito de decifrar as mensagens implícitas e explícitas nos documentos voltados às políticas docentes, valemo-nos dos subsídios teóricos e operacionais apresentados por Shiroma, Campos e Garcia (2005) e Evangelista e Shiroma (2015), os quais investem sobre a "linguagem da política", alertando para a forma contraditória com que os "conceitos e argumentos da reforma" são apresentados e utilizados nos textos, pois de acordo com as autoras:

Analisamos documentos procurando decifrar, nos textos, os objetivos anunciados ou velados de determinada política, para entender como se articulam ou afrontam o projeto hegemônico burguês, como impactam a 
luta de classes, como colaboram ou dificultam a construção de uma sociabilidade que supere o modo de produção capitalista. (EVANGELISTA; SHIROMA, 2015, p. 2)

Dessa forma, após a seleção de relatórios, manifestações oficiais e documentos institucionais provenientes de organismos multilaterais, de corporações, de fundações educacionais e de movimentos sociais, procedemos à leitura detida e pormenorizada dos conceitos, relações e formas de estruturação dos materiais, com vistas à apropriação teórica e à definição das categorias, a partir das quais organizamos os dados da investigação e a exposição dos resultados.

Assim, no primeiro momento, examinamos a vinculação entre a crise que se abateu sobre o sistema capitalista a partir da década de 1970 e suas estratégias de recomposição, em especial aquelas que envolveram a difusão da perspectiva da governança. Em seguida, atemo-nos à busca pelos determinantes que posicionaram a pauta docente no centro do discurso reformador na virada deste novo século. Na terceira seção, enfocamos a caracterização das formulações sobre políticas docentes contidas na agenda contemporânea, a fim de identificarmos os seus traços essenciais. Por fim, à guisa de conclusão, buscamos resgatar os elementos constitutivos do estudo, na forma de uma síntese do fenômeno investigado.

\section{Governança para readequação da governabilidade neoliberal}

De acordo com Netto (2012a, 2012b, 2013), o processo de restauração operado desde o fim dos anos 1970, em decorrência da crise sistêmica que tem atravessado toda a estrutura da "ordem do capital", ao mesmo tempo que tem ampliado a exploração de uma classe por outra, alcançou, em sua ordem social, o esgotamento das possibilidades civilizatórias, constituindo-se, na atualidade, um forte vetor direcionado à reversão de todas as conquistas progressistas obtidas pela humanidade. Diante deste quadro, o intelectual marxista assevera que o capital tem se valido de estratégias que visam salvaguardar o sistema produtivo vigente de possíveis ações das "classes perigosas", entre as quais destacamos aquelas denominadas pelo autor como ações "coesivas e legitimadoras" do enfrentamento à questão social (NETTO, 2012a, 2012b, 2013), ou, como na elaboração de Motta (2012), medidas para "administrar a pobreza". 
Trata-se, como sugere Motta (2012), do reconhecimento por parte da intelligentsia capitalista da insuficiência de uma abordagem exclusivamente economicista para gerir a crise do sistema, exigindo a necessidade da efetivação de ajustes que assumam outros fatores, tais como os sociais, culturais e educacionais. Portanto, consideramos, assim como Borges (2003), Santos (2005) e Shiroma e Evangelista (2014a), que foi nesse contexto, em meio ao recrudescimento das formulações que pautavam a necessidade de readequação da governabilidade neoliberal, cuja vertente ortodoxa mostrou seus limites ao final da década de 1990, que a perspectiva da governança se erigiu.

Em estudo acerca da produção do conhecimento sobre governança nas Ciências Sociais, Levi-Faur (2012) revelou que apesar da disseminação do conceito de governança entre 1986 a 1990, sua elevação exponencial somente veio acontecer com a transição para a década de 1990, a qual foi acompanhada pela propagação de uma vasta gama de pesquisadores, centros de pesquisa, periódicos científicos e conferências dedicadas ao assunto (ANSELL; TORFING, 2016). Dessa forma, pautados em uma estratégia que buscou evitar uma definição demasiadamente estreita ou aberta demais para um número infinito de interpretações contextuais, Ansell e Torfing (2016) conceituaram governança a partir de duas questões centrais: o que é governado e como isto é governado. Logo, a definição dessa prática social se materializou como: "os processos interativos através dos quais a sociedade e a economia são dirigidas para objetivos coletivamente negociados." (ANSELL; TORFING, 2016, p. 4, tradução nossa).

Como se pode notar, ganha destaque nessa acepção as questões de "interação" e “negociação" entre indivíduos/atores, as quais revelam, de fato, os pilares onde vai se erguer a retórica da governança que, subsidiada em um critério formal de participação política, busca diluir os projetos históricos de classes sociais, sob a ilusão do imperativo da troca e partilha de "ideias, recursos e competências" para a produção dos resultados desejáveis, diga-se de passagem, à ordem capitalista.

Ansell e Torfing (2016) ainda ressaltam que uma das principais motivações para o crescimento do uso do conceito de governança foi a fundamental problematização sobre a função e o papel do Estado, a qual, segundo Shiroma e Evangelista (2014a), passou a orientar a edificação das bases de um desenvolvimento e sociabilidade que garantisse a “coesão social”. Logo, falar em governança não implicaria na defesa de um Estado 
mínimo ou na substituição do governo, visto ser este o parceiro legítimo na construção de todo o processo de governança, pois, como explica Santos (2005), caberia ao Estado a responsabilidade de criar o espaço necessário para os entes não estatais intervirem de maneira legítima, ou como na observação de Shiroma e Evangelista (2014a, p. 24-25): “o Estado não se afastou para dar espaço ao setor privado; ao contrário mantém-se presente, mas não como provedor exclusivo dos serviços públicos - entendidos como atendimento ao público -, e sim como regulador”.

Nesse sentido, com base em Santos (2005) e Shiroma e Evangelista (2014a) é possível identificar que as redefinições do papel do Estado e suas relações com a sociedade civil passaram a ocupar função estratégica na composição de novos pactos que garantissem a governabilidade sob os auspícios do capital, visto os limites já sobressalentes do modelo neoliberal.

No que se refere às principais repercussões da lógica dos processos de governança na educação, importantes estudos têm submetido à crítica a associação dessa prática social com aspectos da construção do consenso, da coesão social e da conformação ideológica (BORGES, 2003; MOTTA, 2012; SHIROMA; EVANGELISTA, 2014a), enquanto o professor, como já havíamos indicado, foi destacado como agente indispensável para pôr em curso a reforma educacional pretendida.

\section{0 professor como o redentor educacional no âmbito da governança global}

De acordo com Shiroma, Moraes e Evangelista (2004), desde o início da década de 1990, o Quadro de Ação aprovado pela Conferência Mundial de Educação para Todos (EPT) já sinalizava a suposta necessidade de "melhorar a situação docente", o que foi acompanhado, inclusive, pelos copatrocinadores desse influente espaço deliberativo, como o Banco Mundial (BM), que ajustou suas diretrizes políticas para as décadas subsequentes.

Além disso, as autoras resgatam que, por convocação da Organização das Nações Unidas para a Educação, a Ciência e a Cultura (Unesco), de 1993 a 1996, especialistas de diversas partes do mundo compuseram a Comissão Internacional sobre Educação para o Século XXI com a finalidade de estabelecer uma concepção sobre o papel que a educação 
deveria assumir diante do cenário de incertezas que caracterizavam o final do século, que foi divulgada por meio do relatório denominado Educação: um tesouro a descobrir, ou reconhecidamente Relatório Delors. Para Shiroma, Moraes e Evangelista (2004), neste documento já estavam contidos os indícios da ideia de conferir ao professor a responsabilidade pela realização do ideário do século XXI. No exame dessas intelectuais sobre aquele que ficou conhecido como Relatório Delors, sinalizava-se criticamente o perfil do professor tido como agente de mudança, cujas

[...] principais características seriam competência, profissionalismo, devotamento. Mas, supõe-se que apresente outras competências pedagógicas como empatia, autoridade, paciência e humildade. Um professor edificante, enfim. (SHIROMA; MORAES; EVANGELISTA, 2004, p. 68)

Portanto, considerando o estímulo das políticas educacionais por meio das “condicionalidades" estabelecidas pelo BM e também pela incisiva do Relatório Delors em conceber o professor como agente essencial da mudança educacional, entendemos que os acontecimentos da década de 1990 demarcam o notável ingresso do tema docente nos processos de governança global, seguido da elevação exponencial dessa questão a partir da transição secular.

Para Robertson (2012a, 2012b, 2012c), os anos 2000 revelam uma mudança significativa nas relações de poder e controle sobre a governança dos professores, de modo que, cada vez mais, tem se acumulado evidências da interação de uma ampla gama de "atores globais", que sob a justificativa de que seria necessário "modernizar" os sistemas educacionais e o trabalho dos professores para atender o recente projeto de desenvolvimento das "economias baseadas no conhecimento" e os "desafios do Século XXI", passaram a envidar uma série de iniciativas, com o fim de reajustar as inadequações manifestadas nas intervenções neoliberais desde 1980, não no sentido de estabelecer qualquer superação positiva aos professores, mas na perspectiva de empreender um novo esforço para os fins que se almejava. Robertson (2012C), fundamentada em Jamie Peck e sua obra Construções da razão neoliberal (2010), demonstra que as "falhas neoliberais" tendem a resultar em novas rodadas de intervenção, em um suposto 
movimento de desregulação e re-regulação; de fluxos, refluxos e subcorrentes, auxiliados por mecanismos de acompanhamentos que criam camadas e sobre camadas.

Como demonstrou a autora, as políticas neoliberais iniciadas na década de 1980 em relação aos professores trouxeram profundas marcas no sentido de desencorajar candidatos ao ensino e também acelerar a saída dos que lá estavam. Subsidiada por uma pesquisa divulgada pela Internacional da Educação (IE) em 2012, Robertson (2012b) informou que mesmo em países como Austrália e Estados Unidos, um em cada quatro professores deixavam a carreira do ensino nos primeiros cinco anos. Tal constatação não poderia ser desconsiderada, visto que a escassez de professores poderia colocar em risco o plano reservado à dimensão educacional na estratégia mais abrangente de recomposição capitalista, impondo, assim, o grande desafio da pauta docente para o milênio que se inaugurava: recrutar e reter professores para os sistemas educacionais nacionais sem alterar substancialmente os princípios orientadores neoliberais.

Dessa forma, se por um lado as políticas neoliberais haviam silenciado, sobrecarregado, desvalorizado e mesmo demonizado os professores (ROBERTSON, 2012a, 2012b), a questão se agravava nos "países de baixa renda", que, em meio à expansão do acesso educacional ocasionado pelo compromisso de EPT, sofriam da intensificação de problemas específicos, como no caso da África subsaariana, a qual via seu montante de professores reduzir significativamente devido ao elevado índice de contaminação pelo Vírus da Imunodeficiência Humana (HIV).

O relatório Professores e qualidade educacional: monitorando as necessidades globais para 2015, produzido pelo Instituto de Estatística da Unesco, apresentou, de forma atualizada e com base em uma ampla gama de fontes de dados, que no ano de 2006 a necessidade de recrutamento e formação de professores estava na ordem aproximada de 18 milhões de novos professores para se alcançar as metas planejadas para o ano de 2015, com grande ênfase sobre os países da África Subsaariana, dos Estados Árabes e do Sul da Ásia (UNESCO, 2006).

No intuito de ampliar a mobilização acerca da necessidade de reforma das políticas voltadas aos professores, o imperativo da quantidade logo foi atrelado à qualidade (OCDE; UNESCO, 2001; UNESCO, 2004, 2006). O entendimento divulgado era de que não se tratava apenas de alcançar uma meta em relação ao número de professores, mas que 
caberia aos sistemas educacionais, de forma sustentável e à luz dos recursos disponíveis, desempenharem papel crucial na adaptação dos indivíduos e das sociedades às profundas transformações sociais e também promover o desenvolvimento do capital humano necessário ao crescimento econômico, o que exigia dos professores a capacidade de desenvolver e fornecer conteúdos educativos, de forma a satisfazer as necessidades dos cidadãos de hoje e de amanhã (OCDE; UNESCO, 2001).

Nesse sentido, a demanda docente incorporou-se em uma posição de redentora na conjecturada discussão sobre qualidade educacional, a ideia de que nenhum sistema educacional seria melhor do que os seus professores ganhou forte repercussão, porém sempre atrelada aos "silogismos idealistas" denunciados por Shiroma e Evangelista (2014b), que vinculam, de forma imediata e sem as mediações fundamentais, o desempenho docente e a aprendizagem dos estudantes ao desenvolvimento econômico das nações. A implicação dessa formulação é a nítida responsabilização dos professores não só pelos resultados educacionais, mas também pelo progresso dos países, como sugerem as experts do BM, quando inferem que "a capacidade dos professores de assegurar que seus estudantes aprendam é o elemento sine qua non para os estudantes e os países colherem os benefícios econômicos e sociais da educação." (BRUNS; LUQUE, 2015, p. 7).

Depreende-se dessa discussão sobre o papel dos professores na produção da qualidade educacional que a mesma está conectada à dimensão ideológica. Segundo Schneider (2014), os professores possuem forte potencial insurgente, suscetível de emperrar iniciativas de interesse do capital e engendrar fortes obstáculos para as reformas educacionais. Logo, debilitar tal capacidade por meio dessa retórica aprazível é extremamente estratégico para a reprodução de habilidades e subjetividades exigidas para o funcionamento das engrenagens capitalistas, o que faz dos docentes agentes valiosos ao establishment, que não pode ser relegado.

Outra questão de suma importância que permeia o debate sobre os professores na produção da qualidade tem sido o problema do financiamento educacional, sobretudo, pela demanda docente representar o maior dispêndio dos recursos educacionais, especialmente nos "países em desenvolvimento" (OCDE; UNESCO, 2001; UNESCO, 2004), tornando esse setor um campo extremamente atrativo para os agentes 
do capital. Evangelista (2015) infere que tal concepção de educação transforma a atividade docente em um "bem mercadejável”, isto é, um canal de investimento, que envolve consultorias, produção de currículos, sistemas de educação, apostilas, tecnologias, máquinas, material didático, isto é, reformas educacionais inteiras que podem ser comercializadas em sintonia com a ideia da possibilidade de 'amestrar' o professor (EVANGELISTA, 2015).

Portanto, a confluência desses interesses sobre a questão docente congeminou os esforços institucionais e contribuiu para atear a compleição de uma extensa produção de mecanismos de governança, envolvendo a veiculação de campanhas e programas, a realização permanente de eventos, a produção e gestão de dados, e a efetivação de grupos de trabalhos, com fins de advocacy e accountability, ou seja, ao mesmo tempo que se criou uma aparente atmosfera de promoção e suporte das demandas docentes, legitimou-se o estado de responsabilização dessa categoria.

\subsection{Campanhas e Premiações}

Desde o ano de 1994 tem sido celebrado, a cada dia 5 de outubro, o Dia Mundial dos Professores. A data selecionada é alusiva ao dia da adoção das recomendações da Organização Internacional do Trabalho (OIT)/Unesco relativas ao pessoal docente. Nesse sentido, principalmente, sob direção da própria OIT/ Unesco, da IE e do Grupo de Trabalho Internacional sobre Professores (Internacional Task Force on Teachers), é assumida uma ampla campanha de convocação para comemoração desse dia em todo o mundo, ao mesmo tempo em que se utiliza esse espaço para chamar atenção às questões candentes definidas para aquela edição do Dia Mundial dos Professores.

Os "parceiros" que se somam na convocação dessa atividade enviam uma mensagem conjunta para "homenagear" os professores e conjuntamente abordam os tópicos prioritários da agenda sobre professores. No ano de 2016, por exemplo, concentraram-se sobre o tema: "valorizando os professores, melhorando seu status", o qual chamou atenção para os 50 anos da constituição das recomendações OIT/Unesco e destacou a necessidade de conexão das políticas de professores com a pauta educacional expressa nos Objetivos de Desenvolvimento Sustentável aprovados em 2015. 
Aditado a isso, na sede da Unesco, em Paris, a cada dois anos, durante as celebrações do Dia Mundial dos Professores é entregue o Prêmio Unesco - Hamdan Bin Rashid Al-Maktoum aos projetos destacados na melhora do desempenho e da eficácia dos professores. A candidatura ao prêmio pode ser realizada por pessoas que representam: instituições ou organizações; órgãos internacionais/nacionais ou Organizações não Governamentais (ONGs); instituições educacionais ou de pesquisa; e comunidades em todos os níveis. As nomeações, entretanto, devem ser enviadas somente pelos governos dos Estados membros, em consulta com suas Comissões Nacionais da Unesco, bem como por ONGs que mantenham parcerias oficiais com a Unesco.

Sob o argumento do apoio à melhoria da qualidade do ensino e aprendizagem para a consecução dos objetivos da agenda Educação 2030, a premiação tem se revelado uma forte ação de advocacy em favor dos princípios orientadores para o “desenvolvimento sustentável”. Os projetos premiados no ano de 2018 expressam claramente tal Diretriz, a saber: o Centro de Modelagem Matemática, da Universidade do Chile; o projeto Diklat Berjenjang, da Indonésia; e o Programa rápido de transformação da formação de professores, do Reino Unido. Enquanto o primeiro aborda as lacunas de desempenho em matemática entre estudantes de diferentes contextos socioeconômicos e busca melhorar a qualidade do ensino da matemática em geral, o segundo volta-se à promoção de um desenvolvimento profissional de qualidade dos professores da primeira infância, principalmente nas áreas mais pobres e remotas. Já o terceiro prioriza a formação de professores de Gana, por meio de uma abordagem centrada na criança e em brincadeiras, com vistas à substituição dos métodos disciplinares tradicionais centrados na fala e no giz.

No rol ainda das premiações, chama atenção a iniciativa da Fundação Varkey, braço filantrópico do Grupo Varkey - proprietário da Global Education Management Systems, empresa de consultoria e gestão educacional que opera a maior rede de escolas privadas referente à educação infantil e ensino fundamental no mundo - em conceder, desde 2015, o Global Teacher Prize, autoproclamado o Prêmio Nobel do Ensino, que premia com US\$ 1 milhão o professor que apresentar a prática de ensino considerada “extraordinária" entre aquelas candidatas. 
Os critérios para a escolha do vencedor do Global Teacher Prize são um excelente indicativo do perfil de professor almejado pelas grandes corporações empresariais neste início do Século XXI. Dessa forma, o ensino considerado excelente é aquele que: 1) causa impacto real na vida dos indivíduos, referendado pelos membros escolares ou comunidade em geral; 2) utiliza abordagem inovadora que amplie os resultados da aprendizagem; 3) contribui para amplos debates educacionais, dando voz aos problemas que afetam a escola e a comunidade; 4) encoraje professores e não professores a se manterem ou ingressarem na profissão; 5) prepare os jovens para um mundo cada vez mais diversificado e globalizado, transformando os alunos em cidadãos globais de mentes abertas e bem-sucedidos; 6) melhore o acesso a uma educação de qualidade para crianças de todas as origens por meio do desenvolvimento de ideias e iniciativas inovadoras; e 7) vá além da sala de aula, com uma abordagem verdadeiramente extraordinária da educação, inspirando professores e não professores em todo o mundo.

O projeto educacional colocado em prática pela professora vitoriosa na edição do prêmio em 2017 caracteriza e ratifica bem este perfil. Maggie MacDonnell (Nova Escócia/Canadá), depois de cinco anos de trabalho voluntário na África subsaariana com a prevenção do HIV, decidiu se dedicar ao ensino em uma Aldeia de Inuit (membros da nação indígena esquimó que habitam as regiões árticas do (anadá), chamada Salluit, uma comunidade com população estimada em 1.300 habitantes, que não pode ser alcançada por via aérea. No inverno, as temperaturas alcançam $-25^{\circ} \mathrm{C}$. Em 2015, houve seis suicídios, todos por jovens do sexo masculino entre 18 e 25 anos.

O quadro que a professora encontrou era de condições desfavoráveis, com elevadas taxas de rotatividade docente, professores abandonando seus postos no meio do ano letivo e a sua escola sequer possuía um diretor, o qual estava de licença devido ser acometido por uma alta carga de estresse. A comunidade era afetada por enormes problemas de gênero, como gravidez precoce, abuso sexual e limitação das meninas pelas tarefas domésticas. Em áreas de alta privação, isolamento e recursos limitados, o alcoolismo, tabagismo, ou mesmo o consumo de drogas se fazia frequente entre os jovens.

Diante desse quadro e com uma abordagem que buscava transformar os estudantes de "problemas" em "soluções" por meio de "atos de bondade", Maggie 
melhorou dramaticamente a frequência escolar. As iniciativas envolveram: 1) criação de um programa específico para meninas voltado para o desenvolvimento de habilidades para a vida; 2) captura de financiamento da ordem de US\$30.000 para envolver os alunos no preparo de refeições quentes para a comunidade; 3) parceria com a creche onde seus alunos trabalharam nas salas de aula com profissionais experientes, obtendo valiosa contribuição por meio do processo de mentoria e da compreensão da educação infantil; 4) conquista de US\$ 20.000 para um programa de nutrição na escola onde os alunos preparam lanches saudáveis para os seus colegas estudantes; 5) estabelecimento de um Centro de Fitness para jovens e adultos da comunidade local para a promoção de um estilo de vida mais saudável, aliviando o estresse e ajudando os jovens a se fortalecerem física e mentalmente; 6) participação em treinamento de prevenção suicida e caminhadas em parques nacionais para compreender a administração ambiental; 7) arrecadação de mais de US\$ 37.000 para prevenção de diabetes pelos alunos; 8) Maggie também foi mãe adotiva temporária na comunidade, inclusive para alguns de seus próprios alunos.

Como podemos notar, as características apresentadas pela professora Maggie expressam um projeto de professor no âmbito dos processos de governança global: que assuma o papel de administrador dos problemas sociais; um sujeito capaz de reestabelecer a coesão social e ao mesmo tempo estimular o empreendedorismo, o qual, para isso, precisa ter iniciativa, liderança, resiliência; ser altruísta, visionário e um verdadeiro pacificador.

\subsection{Eventos Internacionais}

Como expressão de mais um mecanismo de governança, ressaltamos duas iniciativas que se integram como faces da mesma moeda. De um lado, o Fórum Internacional de Diálogo Político (Policy Dialogue Forum), o qual tem reunido, desde 2010, os países com os mais severos entraves para a realização da escolarização elementar no planeta, sob a organização do Grupo de Trabalho Internacional sobre Professores para Educação 2030; do outro, a Cúpula Internacional sobre a Profissão Docente (International Summit on the Teaching Profession), a qual tem congregado, desde 2011, os melhores sistemas educacionais, conforme o desempenho obtido no Programa Internacional de 
Avaliação de Estudantes (PISA), sob o impulso da Organização para a Cooperação e Desenvolvimento Econômico (OCDE), juntamente com a representação global dos sindicatos de professores, a IE.

Se, por um lado, o primeiro evento buscou em sua versão inaugural: apresentar uma análise do Relatório de Monitoramento Global da EPT, cuja temática era "alcançando os marginalizados" (UNESCO, 2010); partilhar experiências e práticas dos países em relação ao "financiamento e professores" e à "marginalização e professores para a EPT"; e manter em destaque a pauta docente na agenda política dos países membros do Grupo de Trabalho Internacional, por outro lado, o segundo evento anunciou como objetivo: dar destaque à profissão docente; iniciar um diálogo internacional permanente sobre a profissão docente; promover um intercâmbio aberto e construtivo sobre políticas e práticas desenvolvidas ao redor do mundo para o desenvolvimento de uma profissão de alta qualidade; e examinar formas de envolver os professores na reforma da educação (ASIA SOCIETY, 2011).

A seleção dessas experiências nos parece bastante elucidativa do significado de governança aplicado ao tema das Políticas Docentes, pois se refere à junção insólita de diferentes representações de entes públicos e privados, em interações que fluidificam o antagonismo de projetos históricos de classes sociais, mas que têm um desfecho político claro: a legitimação e o encaminhamento de pautas e demandas pré-definidas, sob a ostentação da ideia amorfa de que houve trocas, partilhas e negociações.

A $5^{\text {a }}$ edição da Cúpula é bem elucidativa da peculiaridade desses eventos. Ao lado do Conselho de Ministros da Educação do Canadá, assumiu a organização da edição do evento The Learning Partnership, uma organização de "caridade nacional” dedicada à construção de parcerias para "apoiar, promover e fazer avançar" a educação financiada publicamente no Canadá. A sua fundação, em 1993, está ligada à necessidade de construir pontes importantes entre líderes em educação e líderes em negócios. Tal concepção ficou bastante clara na estruturação do evento, relatada por Asia Society (2015), com a disposição de telas dos patrocinadores abertas para a exibição aos delegados durante os intervalos, na participação de líderes empresariais, representando a The Learning Partnership, em mesas e espaços de networking, além da organização de sessões paralelas para a grande maioria dos delegados e participantes que privilegiavam 
temáticas, como: “Caminhos sustentáveis na educação para professores”, apresentada pela Pearson Canada, uma empresa líder mundial no desenvolvimento de produtos e serviços para aprendizagem; "Eficácia no uso da tecnologia”, exposta pela SMART Technologies, empresa que ficou conhecida pela produção de quadros interativos; e também "Dimensionando o bom ensino", introduzida pela TES Global, empresa de educação digital que se dedica a apoiar, inspirar e conectar educadores em todo o mundo.

Em síntese, o formato dos eventos se inicia com a divulgação de um documento base, com a finalidade de introduzir os tópicos-chave a serem abordados durante o Encontro. Para o Fórum, o Secretariado do Grupo Internacional sobre Professores prepara uma nota conceitual, geralmente pautada nas formulações sobre a questão docente do Movimento de EPT, transformado, desde 2015, em Agenda Educação 2030. No que se refere à Cúpula, as Diretrizes são dadas por meio das elaborações da OCDE, em um vasto material que combina, segundo a Asia Society (2014), a sistematização de evidências internacionais de pesquisa, das melhores práticas, dos princípios gerais e inovações que poderiam levar a políticas exitosas nessa área.

Com a finalidade de transformar as discussões em ações políticas efetivas nos sistemas educacionais nacionais, os dois Encontros viabilizam espaços para a sistematização de conclusões e recomendações. No entanto, a Cúpula Internacional tem sido mais contundente no sentido de comprometer os participantes com a necessidade das reformas. A partir da sua $2^{a}$ edição foi inserido um espaço exclusivo na programação para reunião dos delegados oficiais de cada país, com o objetivo de estimular a discussão sobre os possíveis desdobramentos do arcabouço teórico-prático acessado durante o evento no âmbito da implementação de políticas nacionais. Na sessão de encerramento, cada delegação deve compartilhar três pontos que incluam o legado mais valioso da Cúpula e as principais prioridades da política docente a serem abordadas em cada país durante o próximo ano.

O formato da Cúpula Internacional é tão original, devido a integrar os ministros da educação e os principais dirigentes sindicais educacionais ao nível dos Estados-nação, que levou, inclusive, o secretário de educação dos EUA, Arne Duncan, ao abrir a Cúpula em 2011, a argumentar que boa parte do 'saber popular' sobre a alegada dificuldade de elevar 
a profissão docente e a presunção de que os sindicatos de professores seriam obstáculos inevitáveis à reforma, estariam equivocadas e, que, as políticas governamentais dos países participantes naquele evento revelavam a possibilidade de se fazer diferente (ASIA SOCIETY, 2011).

Para Robertson (2012a), esse processo de incorporação da IE na agenda de governança global para professores da OCDE, tem se expressado como um importante mecanismo de legitimação e prevenção de atritos, que visa, em última instância, a disposição das melhores táticas para alcançar o espraiamento das "recomendações" dessa Organização.

Dessa forma, enquanto o Fórum de Diálogo Político alcançou a sua $12^{a}$ edição em 2019 na cidade de Dubai, Emirados Árabes Unidos, a Cúpula sobre a Profissão Docente realizou a sua $9^{\text {a }}$ edição na cidade de Helsinque, Finlândia. Portanto, a preservação desse formato de evento internacional, reunindo uma ampla representatividade de instituições públicas e privadas, entes governamentais e não governamentais, sob o argumento da "liderança colaborativa", alimentada pela monumental arquitetura dos dados e suas “evidências exitosas”, demonstra a consolidação de um amplo processo de governança global, envolvendo não apenas as principais potências econômicas mundiais, mas também os países que detêm os maiores bolsões de miséria na periferia capitalista, na tentativa pertinaz de delinear e difundir um perfil de professor adequado para a promoção e/ou manutenção das condições propícias de reprodução do capital.

\subsection{Corrida pela produção do conhecimento}

A mobilização acerca da produção de conhecimento em relação aos indicadores educacionais, em especial, sobre os dados de performance e medidas de qualidade, tem sido tão enfatizado nos processos de governança na contemporaneidade, que conduziu pesquisadores de cinco países europeus -Dinamarca, Escócia, Finlândia, Inglaterra e Suécia - a desenvolverem um amplo projeto de três anos de duração, com a intenção de problematizar o significado dessa nova dinâmica no campo educacional. Como conclusão, o estudo revelou que tais mecanismos têm se configurado como uma poderosa forma de governança que opera na mudança e conformação de espaços políticos e na "fabricação" 
da identidade educacional europeia, com significativas repercussões na atuação de formuladores políticos nacionais, governos locais e professores (OZGA et al., 2011).

Os pesquisadores Ozga, Segerholm e Simola (2011) chamaram atenção para o potencial da combinação do fluxo de conhecimento/dados comparativos e o deslocamento conceitual de educação para aprendizagem, no que se refere ao monitoramento, direcionamento e mudança de culturas e comportamentos. Para tanto, destacaram a importância de compreender as relações entre essas novas formas de governança e a ideia de "autorregulação", pois seria através desta que educação/aprendizagem tem ganhado importância central na conjuntura atual, conectando a esfera individual ao nível supranacional, a fim de constituir a "sociedade como domínio governável." (OZGA; SEGERHOLM; SIMOLA, 2011).

Para os autores, o aspecto-chave dessa forma de governança consistiria em “inculcar novas normas e valores pelos quais mecanismos regulatórios externos transformam a conduta de organizações e indivíduos em suas capacidades como agentes de 'auto atualização'.” (OZGA; SEGERHOLM; SIMOLA, 2011, p. 89, tradução nossa).

O desafio fundamental de alcançar objetivos políticos por meio de ações a distância, também instigou Robertson (2012a) a problematizar como as Organizações Multilaterais, em particular, Unesco, OCDE e BM, atualmente têm buscado influenciar os sistemas educacionais nacionais e seus professores. Seguindo a mesma constatação de Ozga et al. (2011), a caracterização de Robertson (2012a) foi de que dois poderosos mecanismos de governança de professores estão em funcionamento na conjuntura atual, a noção da "aprendizagem como desenvolvimento" e a "comparação competitiva".

Para Robertson, enquanto o primeiro mecanismo

[...] deriva-se do neoliberalismo e suas tecnologias de domínio, os quais se preocupam com o individualismo, escolha e consumo mais do que com os resultados relacionais e sociais, e com auto-responsabilidade mais do que com responsabilidade social. (ROBERTSON, 2012a, p. 20)

O segundo, referente à “comparação competitiva”, funciona como: 1) poderoso enquadramento espacial e alavanca para definir status, no sentido de produzir ordenamento hierárquico entre países e professores performáticos e aqueles de baixo 
desempenho; 2) estabelecimento de uma dimensão temporal na competição, como os ciclos de coleta de dados, que incute a ideia de "aprendizagem para melhorar" e mantém a tensão suficiente no sistema; 3) a dinâmica avaliativa/moral que proporciona a base para julgar em qual posição o país se encontra diante de uma característica e indica onde os países e os professores devem aprender e agir adequadamente; e 4) a integração por escalas (nacionais, regionais e globais) que produzem oportunidades para sua amplificação e poder, em função da sua extensão e alcance, conduzindo a soberania e autoridade para além do domínio nacional e do professor, para situá-los em âmbito global (ROBERTSON, 2012a).

Ao comparar as tecnologias de governança de professores produzidas pelo Instituto de Estatística da Unesco, a Abordagem de Sistemas para Melhores Resultados Educacionais (SABER) voltado ao tópico docente (SABER-Teachers), do Banco Mundial, e a Pesquisa Internacional sobre Ensino e Aprendizagem (Talis), da OCDE, Robertson (2012a, p. 22) avalia que, apesar da convergência de agendas, suas ações são desuniformes em relação à finalidade, ao conteúdo e aos resultados para os professores, que têm provocado uma "topografia desigual e sobreposta dos trabalhos dos professores". Para a socióloga britânica, essas diferenças denotam a história, os acordos assumidos com o projeto político neoliberal, relacionamentos com os Estados-nações e outras corporações, bem como suas capacidades de garantir determinados compromissos para os projetos de governança.

A autora ainda explica que, enquanto a Unesco teve sua trajetória associada ao projeto educacional para "universalidade" e de apoio aos direitos humanos e de uma cultura unificadora global, o Banco Mundial, adepto do mercado livre e regulação mínima do Estado, sempre enfrentou a desconfiança da inserção de um banco na esfera educacional, desenvolvendo uma linha voltada ao investimento em capital humano. Quanto à OCDE, Robertson (2012a, p. 15) vincula tal Organização ao pensamento ordoliberal europeu, que optava por "uma forma mais humanista do mercado, enraizada no fato que as plenas capacidades do mercado podiam ser materializadas quando postas numa ordem legal e social firme".

Consequentemente, Robertson (2012a) defende que tais perspectivas vão implicar em atuações díspares no que diz respeito às políticas de professores. Apesar de todas 
coletarem, administrarem, avaliarem e apresentarem dados estatísticos sobre o trabalho do professor, as "tecnologias" utilizadas encorajam tipos de conversações e comprometimentos diferenciados nos sistemas nacionais, devido às suas lógicas de intervenção e políticas espaciais e temporais desiguais. Sendo assim, o grande desafio colocado a tais Organizações seria de "como" assegurar a implementação e causar as mudanças nas políticas nacionais sobre professores, mitigando os possíveis atritos.

A pesquisadora relaciona o poder desses mecanismos de governança, que se valem de classificações (rankings) e indicadores (benchmarks), à sua capacidade de atuar como "aviões militares não tripulados" (drones), os quais são cada vez mais desejáveis em espaços com obstáculos para a luta militar, devendo cumprir a tarefa de se "[...] embrenhar nas fronteiras nacionais não apenas como coletores de dados, mas como agentes à distância, quando são capazes de modular, direcionar, agir, refinar e redirecionar sem estarem presentes fisicamente." (ROBERTSON, 2012a, p. 22).

Na direção do que tem observado Robertson (2012a), poderíamos comparar a busca incessante das Organizações Multilaterais pela produção de dados educacionais para governança como uma "corrida armamentista", em alusão ao estímulo vivido no período conhecido como Guerra Fria (1947-1991), quando a disputa pela supremacia política entre Estados Unidos e União Soviética desenvolveu um arsenal bélico com capacidade de destruição superior ao que o próprio planeta Terra poderia suportar. Dessa vez, a cena parece se repetir e, ao que tudo indica, a grande monta de avaliações, métricas e padrões de referência já começa a evidenciar todo o seu poderio de controle sobre os professores e o seu trabalho educativo.

Ao analisar o "jogo de poder" e as "regras" que envolvem os "atores do conhecimento" por influência e recursos no campo da interação e interconexão dos aparatos de dados, Grek (2016) demonstra que a disputa que abrange as Organizações Multilaterais - no caso da sua análise, OCDE e Comissão Europeia - não está relacionada apenas à ampliação da capacidade de produção de conhecimento, mas, principalmente, ao impacto deste na esfera da governança, o que explica, em certa medida, o ingresso cada vez mais frequente das fundações filantrópicas das grandes corporações empresariais neste universo, como demonstrou Robertson (2012b) sobre o enorme investimento da Fundação Bill e Melinda Gates na produção de um sistema de avaliação 
de professores. As "medidas de ensino eficaz", reunindo uma quantidade sem precedentes de dados sobre professores e estudantes em seis grandes distritos escolares nos Estados Unidos receberão cerca de US\$ 335 milhões da Fundação.

Portanto, como se pode notar, se não fosse suficiente a extensiva atividade de inculcação dos propósitos políticos que deveriam ser assumidos pelos sistemas educativos empreendida por parte das Organizações Multilaterais, temos nos defrontado com a entrada em cena, de modo cada vez mais intenso, da classe empresarial, com uma clara investida na disputa efetiva pela conformação de sua agenda no desenho das políticas públicas para a categoria docente.

\subsection{Grupo de Trabalho Internacional sobre Professores}

Constituído, originalmente, em 2008, no âmbito do Movimento de EPT (19902015), com o propósito de responder às questões referentes à escassez de professores, o Grupo de Trabalho Internacional sobre Professores foi pensado como uma aliança global voluntária de parceiros, a fim de coordenar uma série de medidas interligadas de recrutamento, treinamento, alocação e retenção de professores, buscando, assim, evitar a sobreposição de atividades, em especial, ao nível regional.

Segundo Townsend (2012), quatro foram os aspectos que convergiram para o estabelecimento dessa iniciativa: 1) a existência de um grupo de pessoas articuladas a fim de localizar a pauta docente em um lugar mais central na agenda da EPT; 2) a Noruega, país anfitrião da reunião que estabeleceu o referido Grupo de Trabalho, defendeu que o evento deveria identificar ações efetivas como resultado de cada discussão, afirmando, inclusive, a disposição do país em apoiar financeiramente tais iniciativas; 3) a Unesco, nas discussões sobre o orçamento para o seu novo ciclo financeiro, sinalizou que, em detrimento de uma intervenção sobre várias questões educacionais, priorizaria menos iniciativas com uma abordagem de maior qualidade, indicando como uma de suas prioridades a questão docente; e 4) a disponibilidade de financiamento para uma ação efetiva e com arranjos estruturais inovadores no âmbito da EPT proveniente de acordos firmados entre Comissão Europeia e Unesco. 
Embora o primeiro período de atividade do Grupo tenha sido marcado por um lento desenvolvimento em função da morosidade do financiamento e incertezas de ordem administrativa, Townsend (2012) registra que a efetivação de mudanças no Secretariado e a instalação de um processo de avaliação externa possibilitou a reorientação das atividades do Grupo a partir de 2011. Com o reajuste dos objetivos e melhor definição das atribuições e expectativa dos envolvidos, a nova estratégia passou a enfatizar três linhas de ação principais sobre o tema docente: advocacy e coordenação com iniciativas globais e regionais; criação e disseminação de conhecimento; e facilitação do acesso dos países ao suporte técnico (TOWNSEND, 2012).

De acordo com o plano estratégico, definido para uma intervenção de 2013 a 2016, a articulação entre as três linhas se daria pela ênfase, análise e documentação das experiências e resultados das investigações dos países sobre as questões e temas fundamentais sobre a "força docente", a saber: formação de professores e desenvolvimento profissional; status dos professores e condições de trabalho; gestão de professores; financiamento do ensino e professores; monitoramento e avaliação das políticas e práticas docentes; inclusão e equidade nas políticas e práticas docentes (GRUPO DE TRABALHO INTERNACIONAL SOBRE PROFESSORES, 2014).

Apesar da adoção dos Objetivos de Desenvolvimento Sustentável, especialmente em relação à meta 4.c, sobre os professores, tenha ajustado a missão do Grupo de Trabalho Internacional em direção ao atendimento desse marco internacional, o novo plano estratégico (2018-2021) preservou, de modo geral, as três linhas de ação principais, dando destaque para a definição de objetivos específicos, resultados esperados e iniciativas emblemáticas em cada um desses eixos, com vistas a assegurar um plano estratégico mais operacional. Nessa perspectiva foi traçado um objetivo exclusivo voltado ao fortalecimento da governança do Grupo de Trabalho, o qual apontou medidas para: atuação dos coordenadores, criação de grupos temáticos, fortalecimento dos mecanismos de apresentação dos relatórios, questões administrativas, estratégias de comunicação e suporte, e estratégias de mobilização de recursos (GRUPO DE TRABALHO INTERNACIONAL SOBRE PROFESSORES, 2018).

Portanto, em pouco mais de uma década de atividades, o Grupo de Trabalho sobre Professores tem acumulado uma série de ações de advocacy sobre o tema docente, que 
envolvem: parceria com outras Organizações Internacionais; apoio a países mais distantes no que se refere à busca pelos objetivos previstos nos pactos internacionais da Educação, em especial, para lidar com a falta de professores; investigação e estudos, com vistas a facilitar o acesso aos resultados de pesquisas e ao trabalho analítico para informar as políticas e práticas sobre os professores, com destaque para a publicação do "guia de desenvolvimento de políticas para professores." (GRUPO DE TRABALHO INTERNACIONAL SOBRE PROFESSORES, 2016, tradução nossa); diálogo político e compartilhamento de conhecimento, com a realização de reuniões de especialistas para aprofundar sobre temas específicos relacionados aos professores e ao ensino, com o fim de constituir uma base para a política e melhoria da prática; contribuição para a realização de fóruns regionais para informar políticas, estratégias e planos para preencher a lacuna de professores no mundo; e a efetivação do Fórum Internacional de Diálogo Político.

Dessa forma, considerando o seu foco nas possiblidades de cooperação Sul-Sul e Norte-Sul-Sul (GRUPO DE TRABALHO INTERNACIONAL SOBRE PROFESSORES, 2011), o seu financiamento majoritário por parte da Comissão Europeia, Noruega, Alemanha e França (TOWNSEND, 2012), a sua ampla capilaridade, que envolve na atualidade 54 organizações e 67 países (incluindo o Brasil), com preponderante envolvimento dos países subsaarianos, e a administração de uma Secretaria Executiva hospedada na sede da Unesco, pode-se inferir que estamos diante de uma iniciativa que tem se consolidado, com vistas a responder, principalmente, a situação dos professores dos países mais miseráveis do planeta, o que contribui para ratificar a nossa hipótese de que os docentes são fundamentais na estratégia capitalista para a produção de coesão e legitimação social.

\section{Conclusão}

Ao longo desta exposição, as evidências reveladas sobre o fenômeno em questão permitiram-nos constatar que a congeminação de mecanismos de governança e do número de agentes globais e nacionais em atividade transfronteiriça, com o propósito de operar uma abrangente transformação institucional e normativa nos sistemas educacionais nacionais, em especial sobre o tema docente, está relacionada com a 
finalidade última de manutenção da hegemonia burguesa, por meio da intensificação do processo de exploração capitalista dos bens e serviços públicos e da reprodução ampliada das condições técnicas e ético-políticas necessárias ao modo de produção vigente.

Ao se pautar em um forte viés ideológico, a perspectiva da governança tem buscado obscurecer sua absoluta submissão aos desígnios do mercado e ao caráter restritivo e tendencioso das formas de participação política, por meio da utilização de um instrumental conceitual que sugere responsabilidade social e da efetivação de mecanismos arquitetados de interação, parceria e negociação, que tenderiam à prevalência dos interesses privados.

Devido à sua relevância não apenas por forjar as condições técnicas que permitem à força de trabalho colocar em funcionamento a máquina produtiva, mas também pelo seu potencial de incutir o consentimento necessário para a dominação ideológica da classe trabalhadora, o professor, içado ao posto de redentor educacional, tem sido realçado como imprescindível para compatibilizar os sistemas educacionais com o papel desempenhado pelos diferentes países na economia global. Trata-se, portanto, de fazer com que as mudanças pretendidas atinjam as crianças e jovens submetidos à escolarização, isto é, revela-se uma estratégia sobre a formação da força de trabalho atual e futura, com o objetivo de potencializar as vias de reprodução das condições necessárias ao capital, de modo que a próxima geração de estudantes-trabalhadores apresente o perfil ideal para responder às exigências das atuais relações de produção.

Dessa forma, diante do custo social e político da governança para a classe trabalhadora e para a categoria docente, em específico, torna-se cada vez mais imprescindível o desenvolvimento de condições subjetivas favoráveis a uma saída revolucionária da ordem existente, o que demanda a utilização dos diferentes recursos e meios disponíveis para a elevação da consciência dos trabalhadores sobre sua condição social, sobretudo, na esfera educacional. 
ANSELL, Christopher; TORFING, Jacob. Introduction: theories of governance. In: ANSELL, Christopher; TORFING, Jacob. Handbook on theories of governance. Cheltenham:

Edward Elgar, 2016. p. 1-17.

ASIA SOCIETY. Improving teacher quality around the world: the international summit on the teaching profession (ISTP). [S.I.], mar. 2011. Disponível em:

https://asiasociety.org/global-cities-education-network/international-summit-teachingprofession. Acesso em: 2 abr. 2020.

ASIA SOCIETY. Excellence, equity, and inclusiveness: the international summit on the teaching profession (ISTP). [S.I.], mar. 2014. Disponível em: https://asiasociety.org/globalcities-education-network/international-summit-teaching-profession. Acesso em: 2 abr. 2020.

ASIA SOCIETY. Implementing highly effective teacher policy and practice: the international summit on the teaching profession (ISTP). [S.I.], mar. 2015. Disponível em: https://www.google.com/search?client=safari\&rls=en\&q=Implementing+highly+effective+ teacher+policy+and+practice:+the+international+summit+on+the+teaching+profession+(I STP).\&ie=UTF-8\&oe=UTF-8. Acesso em: 2 abr. 2020.

BORGES, André. Governança e política educacional: a agenda recente do banco mundial. Revista Brasileira de Ciências Sociais, São Paulo, v. 18, n. 52, p. 125-138, jun. 2003.

BRITO NETO, Aníbal Correia. Política nacional de formação de professores no Brasil (2003-2016) como expressão da governança global. 2018. Tese (Doutorado em Educação -Programa de Pós-Graduação em Educação, Universidade Federal de Santa Catarina, Florianópolis, 2018. Disponível em: https://repositorio.ufsc.br/handle/123456789/193601. Acesso em: 7 abr. 2020.

BRUNS, Barbara; LUQUE. Javier. Professores excelentes: como melhorar a aprendizagem dos estudantes na América Latina e no Caribe. Washington, DC: Banco Mundial, 2015. Disponível em: https://openknowledge.worldbank.org/handle/10986/20488. Acesso em: 2 abr. 2020.

EVANGELISTA, Olinda. Formação de professores: um bem mercadejável? In: SEMINÁRIO ESTADO E EDUCAÇÃO, 4., 2015, Florianópolis. A contrarreforma do Estado e os impactos na educação pública. Anais [...] Florianópolis: Andes-SN, 2015. Mimeografado.

EVANGELISTA, Olinda; SHIROMA, Eneida. O. Subsídios teórico-metodológicos para o trabalho com documentos de política educacional: contribuições do marxismo. In: REUNIÃO ANUAL DA ASSOCIAÇÃO NACIONAL DE PÓS-GRADUAÇÃO E PESQUISA EM EDUCAÇÃO, 4., 2015, Florianópolis. Anais [...] Florianópolis: Andes-SN, 2015. Texto para o minicurso do GT 9 - Trabalho e Educação: contribuições do marxismo para a análise de políticas educacionais. Mimeografado. 
GREK, Sotiria. Atores do conhecimento e a construção de novos cenários de governança: o caso da direção-geral de educação e cultura da comissão europeia. Educação \& Sociedade, Campinas, v. 37, n. 136, p. 707-726, jul./set. 2016.

GRUPO DE TRABALHO INTERNACIONAL SOBRE PROFESSORES. Ensuring equity in country policies and practices for providing quality teachers: toward achieving the EFA goals by 2015. In: INTERNATIONAL POLICY DIALOGUE FORUM, 3., Bali: UnesCo, 2011. Anais [...] Paris: EFA, 2011, p. 1-4. Disponível em: https://teachertaskforce.org/knowledgehub/3rd-international-policy-dialogue-forum-concept-note. Acesso em: 2 abr. 2020.

GRUPO DE TRABALHO INTERNACIONAL SOBRE PROFESSORES. Strategic plan: second phase of action (2014-2016). Bali: Unesco, 2014. Disponível em: https://teachertaskforce.org/knowledge-hub/strategic-plan-second-phase-action-20142016. Acesso em: 2 abr. 2020.

GRUPO DE TRABALHO INTERNACIONAL SOBRE PROFESSORES. Guia para o desenvolvimento de políticas de docência. Paris: Unesco, 2016. Disponível em: https://unesdoc.unesco.org/ark:/48223/pfo000235272_por. Acesso em: 20 fev. 2017.

GRUPO DE TRABALHO INTERNACIONAL SOBRE PROFESSORES. Strategic plan (20182021). [S. I.]: Unesco, 2018. Disponível em: https://teachertaskforce.org/knowledgehub/strategic-plan-2018-2021-0. Acesso em: 2 abr. 2020.

LEVI-FAUR, D. From “big government" to "big governance”? In: LEVI-FAUR, D. The oxford handbook of governance. New York: Oxford University Press, 2012. p. 3-18.

LOMBARDI, José Claudinei. Educação, ensino e formação profissional em Marx e Engels. In: LOMBARDI, José Claudinei; SAVIANI, Dermeval (orgs.). Marxismo e educação: debates contemporâneos. Campinas: Autores Associados; HISTEDBR, 2005. p. 1- 38.

MOTTA, Vânia. Ideologia do capital social: atribuindo uma face mais humana ao capital. Rio de Janeiro: EDUERJ, 2012.

NETTO, José Paulo. Capitalismo e barbárie contemporânea. Argumentum, Vitória, v. 4, n. 1, p. 202-222, jan./jun. 2012 a.

NETTO, José Paulo. Crise do capital e consequências societárias. Serviço social e sociedade, São Paulo, n. 111, p. 413-429, jul./set. 2012b.

NETTO, José Paulo. Uma face contemporânea da barbárie. Novos Rumos, Marília, v. 50, n. 1, p. 1-39, jan./jun. 2013.

OCDE; UNESCO. Teachers for tomorrow's schools: analysis of the world education indicators. world education indicators programme. [S.I.]: Unesco Institute For Statistics, 2001. Disponível em: http://uis.unesco.org/sites/default/files/documents/teachers-fortomorrows-schools-analysis-of-the-world-education-indicators-2001-en_2.pdf. Acesso em: 2 abr. 2020. 
OZGA, Jenny. et al. Fabricating quality in education: data and governance in Europe. New York: Routledge, 2011.

OZGA, Jenny.; SEGERHOLM, Christina; SIMOLA, Hannu. The governance turn. In: OZGA, Jenny. et al. Fabricating quality in education: data and governance in Europe. New York: Routledge, 2011. p. 85-95.

ROBERTSON, Susan L. "Situando" os professores nas agendas globais de governança. Teoria e Prática da Educação, Maringá, v. 15, n. 2, p. 9-24, maio/ago. $2012 a$.

ROBERTSON, Susan L. 'Placing' teachers in global governance agendas. Bristol: Centre for Globalisation, Education and Societies, University of Bristol, 2012b. Disponível em: https://goo.gl/1QrwjL. Acesso em: 2 abr. 2020.

ROBERTSON, Susan. L. Teachers' work, denationalisation, and transformations in the field of symbolic control: a comparative account. Bristol: University of Bristol, 2012C. Disponível em: https://susanleerobertson.files.wordpress.com/2012/07/2012-robertsonteachers-denationalisation.pdf. Acesso em: 2 abr. 2020.

SANTOS, Boaventura de Sousa. A crítica da governação neoliberal: o fórum social mundial como política e legalidade cosmopolita subalterna. Revista Crítica de Ciências Sociais, Coimbra, n. 72. p. 7-44, 2005. Disponível em: http://rccs.revues.org/979. Acesso em: 2 abr. 2020.

SAVIANI, Dermeval. Pedagogia histórico-crítica: primeiras aproximações. 11. ed. rev. Campinas: Autores Associados, 2011.

SCHNEIDER, Mara Cristina. Avaliação docente no Brasil e em Portugal: análise das políticas e dos obstáculos políticos. 2014. 409 f. Tese (Doutorado em Educação) Universidade Federal de Santa Catarina, Florianópolis, 2014.

SHIROMA, Eneida; CAMPOS, Roseane F.; GARCIA, Rosalba Maria Cardoso. Decifrar textos para compreender a política: subsídios teórico-metodológicos para análise de documentos. Perspectiva, Florianópolis, v. 23, n. 2, p. 427-446, jul./dez. 2005.

SHIROMA, Eneida; EVANGELISTA, Olinda. Estado, capital e educação: reflexões sobre hegemonia e redes de governança. Revista Educação e Fronteiras, Dourados, v. 4, n. 11, p. 21-38, maio/ago. 2014a.

SHIROMA, Eneida; EVANGELISTA, Olinda. Apresentação - luzes que desiluminam: uma análise dos slogans na política educacional. In: EVANGELISTA, O. (org.). O que revelam os slogans na política educacional. Araraquara, SP: Junqueira \& Marin, 2014b. p. 11-20.

SHIROMA, Eneida; MORAES, Maria Célia Marcondes; EVANGELISTA Olinda. Política educacional. 3 ed. Rio de Janeiro: DP\&A, 2004. 
TAFFAREL, Celi Nelza Zulke. A formação do profissional da educação: o processo de trabalho pedagógico e o trato com o conhecimento no curso de Educação Física. 1993. 301 f. Tese (Doutorado em Educação) - Universidade Estadual de Campinas, Campinas, 1993.

TOWNSEND, Tony. Evaluation of the international task force on 'teachers for education for all' (EFA): Final Report. Paris: Unesco, abr. 2012. Disponível em:

https://teachertaskforce.org/knowledge-hub/evaluation-international-task-force-teacherseducation-all-efa. Acesso em: 2 abr. 2020.

UNESCO. Education for all: the quality imperative. EFA global monitoring report 2005. Paris, 2004. Disponível em: https://unesdoc.unesco.org/ark:/48223/pfo000137333. Acesso em: 2 abr. 2020.

UNESCO. Instituto de estatística. Teachers and educational quality: monitoring global needs for 2015. Montreal: Unesco, 2006. Disponível em:

http://uis.unesco.org/sites/default/files/documents/teachers-and-educational-qualitymonitoring-global-needs-for-2015-en_o.pdf. Acesso em: 2 abr. 2020.

UNESCO. Reaching the marginalized. EFA global monitoring report 2010. Paris: Unesco, 2010. Disponível em: https://unesdoc.unesco.org/ark:/48223/pfooo0186606. Acesso em: 2 abr. 2020.

Recebido em: 10/04/2020 Aprovado em: 06/05/2020

Universidade do Estado de Santa Catarina - UDESC Programa de Pós-Graduação em Educação - PPGE

Revista Linhas

Volume 21 - Número 46 - Ano 2020 revistalinhas@gmail.com 